\title{
Reflections on violence and suicide in South Yorkshire: (Dis-)United Kingdom
}

\author{
By Simon J. Charlesworth
}

This paper addresses the personal consequences attendant upon the post-Thatcher neo-liberal restructuring of the British economy. Its focus is upon the way that increased economic insecurity created a range of personally encountered problems, which constitute the most immediate sense of being-in-a-world so disclosed. It tries to cast light upon the increased anonymous violence that is a pervasive aspect of British public life.

\section{Impersonal lives: anonymous violence}

I would like to consider the possible context of three suicides that took place within a one-month period in South Yorkshire. It was only writing in response to the death of a local man that I began to realise that there were striking parallels in these three deaths. I'd like to consider the context of these deaths and reflect on the meanings that issue from the context of their lives. I want to suggest that it is the personal inflection of particular economic conditions that have led to the malaise that constitutes the hopelessness of many within northern Britain. Recognition is a vital aspect of human personhood and I believe that too many are condemned to anonymous impersonal lives that produce a violence as anonymous as the lives of those who struggle to realise a form of recognition in infraction and violence amidst conditions that are close to chaotic in their personal form, however hidden those forms are by their form.

In this paper I will argue that there is an aggression immanent to the interpersonal relations in British culture that originates in the forms constitutive of our public culture, such that the symbolic violence immanent to the processes that consign people to marginal economic positions and locations finds points of expression, usually involving those rendered victims by these conditions, as their rage is manifest in impersonal violence that seems to have no cause and is therefore, 'senseless'. After an outbreak of violence in the village, I asked one of the staff at the local Weatherspoon's ${ }^{1}$ what he thought of the trouble:

Tha's got t' adopt a military mentality, it's fun dealin' wi' trouble; even when tha' gets in, tha's got t' cut thiseln' off, an' think, Ah can't let 'em dahn, Ah've got t' bi back in mornin'.

What is striking here is the kind of siege mentality that seems to be characteristic of English society, as the divided regions segregated by the interpersonal processes constitutive of our economic segregation, fear and loath one another in relation to the immediacies of responses that manifest what they elicit.

\footnotetext{
${ }^{1}$ A chain of pubs in the UK that the working class tend to go to because their prices are, on average, half that of other pubs.
} 
Bourdieu has spoken of the need to offer people 'the possibility of taking on their habitus without guilt or suffering', and of a 'sense of inadequacy' originating in a 'dispossession that cannot recognise itself as such' (1993:24, original emphasis). Moreover, he goes on to talk about a habitus that,

continuously thwarted by the situation, may be the site of explosive forces (resentment) which may await (and even look for) the opportunity to break out $^{2}$ and which express themselves as soon as the objective conditions for this (e.g. the power of an authoritarian foreman) are offered. (The social world is an immense reservoir of accumulated violence, which is revealed when it encounters the conditions for its expression.) (ibid:87)

The aggression that seems an endemic part of English culture, originates in the quality of the relationships that originate in differences of income and rank, as the following testimony from a 30-year old self-employed IT specialist manifests:

\begin{abstract}
Ah've gev up goin' aht, what is the're? A wrong glance yer'll bi faitin', yer stood the'er it can gu either way, yer might get glassed, yer allous the'er, yer can't relax, yer need fo' five 'er yer t' bi aht t' watch each others' back, just to mek sure yer safe: it gets more dear just to try an' get away from them tranna degrade each other. Ah can see why people spend money to go to places where yer can just relax without the threat, Ah can see that now. What the rich du, is ohnny way, get away from us, cos it's all fucked nahr at this level.
\end{abstract}

The violence issues from the sense deposited in judgements that are detected as postures and glances that issue from the background familiarity with the hierarchy that issues from the way in which, in the UK, income is used to constitute differences of meaning that are a prelude to association and thus to a degradation that is finally felt and, in turn, fought over as the insulted and unrecognised attempt to realise a victory over an alienated being-for-others that will always be pyrrhic. In this paper I will look at some of the atomising consequences of the culture that neo-liberalism fosters.

\title{
2. Neo-liberalism, anti-collectivism and the interpersonal
}

I would like to try and indicate the personal conditions that I believe are behind these explosions of urban disturbance, and relate them to an economic condition that is too often separated from its personal conditions of effectiveness. I would like to do this by beginning with the details of an isolated suicide.

On Tuesday 18 May 2004, an unemployed man in Wath, an ex-pit village in South Yorkshire, committed suicide. He would have left school in the early 1980s to the highest levels of youth unemployment in British history and so was part of the generation constituted in the following data:

\footnotetext{
2 It is perhaps worth noting that three of the four suicide bombers who bombed London on the 7 July 2005 came from the Yorkshire communities that I have myself written about. Despite being accused of sympathies for the British National Party (Kirk 2004:347), I have always been involved in the Asian population in South Yorkshire, doing fiddle jobs for them and carrying out many interviews with them, as well as helping to draft a letter for the Pakistan Advice Centre, Firvale, Sheffield, in order to defend it from closure. But, again, the distances constitutive of the academic gaze leave the world eminently colonisable, in order to produce institutional capital, part of which is the withholding of capital through the canvassing of support for legitimate views of outsiders.
} 
Although suicide rates are often inversely associated with violence against others, in Britain suicide rates among young men 15-24 years old rose by 75 per cent during the mid and late 1980 s... The rise in suicide is likely to have been particularly closely related to rising unemployment... (Wilkinson 1996:162)

There is something distasteful in such a stark rise in the suicide rate of a particular group being explicated in terms as ambiguous as the causal factor 'rising unemployment'. The incapacity of professors of public health, as illustrated in the quote above, to represent a phenomenon of such intense personal significance with anything like terms suited to its gravity, arises from the distances that leave the lives of the poor so mysterious that they have to be 'discovered' through data-generation. In other words, it is the political condition of this group that allows them to be endlessly constituted in data-serving the institutional interests of 'experts'.

In the month in which I compiled a response to the suicide, there were two more suicides reported in the local newspaper. The first was described in the following terms:

A 21-year old facing a court hearing was found hanging from a tree, an inquest heard.

Unemployed Karl Garner...was found hanged...at about 4.30am on Sunday morning... His Mum...said: 'He used to go out drinking a lot and he was due to go to court for something he had not done and I think that was playing on his mind. He also had a lot of financial worries and owed about $£ 1,000$.' (The Advertiser, Friday 18 June 2004)

Anonymous, impersonal deaths, issuing from the same intimate conditions of an existence devoid of value and thus of the very possibility of opportunity and therefore hope (Bourdieu 2005:5). Here we have the triumvirate of working class ${ }^{3}$ pain in a commodity economy: the strain of criminal activity to alleviate the necessity of needing resources to accede to a recognised form of existence, the debt it begets, and drugs (Charlesworth 2006) to cope with the physiological effects of the strain of an asocial form of existence:

A manic depressive who had stopped taking his medication was found hanging from the fence of a Rotherham school.

An inquest heard that 22-year old Gareth Turner had used blue nylon cord from the perimeter fence around the playing fields of Dinnington Comprehensive School.

Gareth, who had been drinking on the evening before his body was found, had telephoned both his parents and his girlfriend last Friday evening.

...[The man's mother] said: 'He asked her if she'd stay at my house and she said no.'

'He said the next time she'd see him he'd be in a box.'

...Pc Martin Moody told the court that around 4am last Saturday morning he was called to the junction of Leys Lane and Doe Quarry Lane, Dinnington,

\footnotetext{
${ }^{3}$ By 'working class' I mean unskilled, semi-skilled and skilled manual workers, which the UK Registrar General defines as social classes IIIM, IV and V. The testimony I use should not be taken as representative of the day-to-day experience of every member of these three classes. I am aware of course that class fractions exist within the working class and that some sections enjoy relative affluence.
} 
after two men had discovered a body hanging from the wrought iron school fence. (The Advertiser, Friday 11 June 2004)

West has spoken of lives constituted by 'the lived experience of coping with a life of horrifying meaninglessness, hopelessness, and ... lovelessness' (West 1993:14). Social valuelessness leads to isolation and isolation has profound consequences:

\begin{abstract}
...there is a happiness in activity which exceeds the visible profits... which consists in the fact of emerging from indifference (or depression), being occupied, projected towards goals, and feeling oneself objectively, and therefore subjectively, endowed with a social mission. To be expected, solicited, overwhelmed with obligations and commitments is not only to be snatched from solitude or insignificance, but also to experience, in the most continuous and concrete way, the feeling of counting for others, being important for them, and therefore in oneself, and finding in the permanent plebiscite of testimonies of interest-requests, expectations, invitations-a kind of continuous justification for existing.
\end{abstract}

But, to bring to light the effect of consecration, capable of rescuing one from the sense of the insignificance and contingency of an existence without necessity, one could, rereading Durkheim's Suicide...observe that the propensity to commit suicide varies inversely with recognized social importance and that the more that agents are endowed with a consecrated social identity...the more they are protected against a questioning of the sense of their existence... The social world gives what is rarest, recognition, consideration, in other words, quite simply, reasons for being. It is capable of giving meaning to life... One of the most unequal of all distributions, and probably, in any case, the most cruel, is the distribution of symbolic capital, that is, of social importance and of reasons for living... (Bourdieu 2000a:240242)

There is 'no worse deprivation, no worse privation...than that of the losers in this...struggle for recognition', because money is not available, they have no way to accede to the interpersonal forms available even to the poor, and they humiliate themselves further in a desperate search for recognition: to scrape themselves together in a failed imitation of sociality, approaching strangers in pubs and being grateful for the merest form of patronised sociality, 'Ah can't cope...thanks fo' bein' a friend, yer welcome at ma 'ouse anytime...' At this level they humiliate themselves for recognition: not money: they are experientially devastated by the nature of their experience of their essence because they are social creatures whose access to being is mediated via sense: meaning.

I wish to contextualise three local suicides in terms of the words of people from the locality in which they lived: a locality in which one can be in a pub of 50 people in which five have lost siblings to heroin. The challenge that such lives pose are urgent, politically, and yet they are the least understood, humanly, in the contemporary political and intellectual climate. My paper poses a question to those who read this journal: Can resources drawn from contemporary social and political theory help us to understand the immediate experience of particular individuals caught in the contemporary forms of a rapidly dividing European culture? And, moreover, as people privileged with access to the resources to signify, do we owe a duty to those who cannot represent the nature of their own lives because they are excluded from the institutions of culture? Obviously, I manifest the importance of those whose ideas have enabled me to signify the phenomena that underlie these diffuse phenomena: 
phenomena that I argue can be integrated once we understand the repercussions, on an interpersonal level, of changes in the social fabric that income mediates.

Throughout this paper, therefore, I will follow Bourdieu and his influences, Heidegger (1962), Merleau-Ponty (1962) and Hegel (1977), in privileging the interpersonal, recognition and negation. Hegel associated recognition with self-consciousness and personhood: people seek recognition in sense and thus are open to negation: the denial of worth and a sense of validity: this allows us to see the person as always in the grip of affective transactions that can, as these deaths show, confound any realm of human possibility (see Charlesworth 2000a, 2000b, 2004, 2005, 2006, and Charlesworth, Gilfillan and Wilkinson 2004). Obviously, dealing with recognition in the context of structured inequality implies a notion of the interpersonal constitution of visibilities: forms of sense, publicly instantiated, which constitute the terms of perception and understanding. I will try to allow the reader to be sympathetic to what the poor actually face and then conclude with some more general points about the state of our political and civic institutions as these now exist in the UK. The final quotation of the piece I believe to be one of the most insightful summations of why the British working class do not go out and vote for any political party. However, first, let me present a note on method.

\section{A note on method}

It is my opinion that what gets classed as 'methodology' is a range of issues that are not really methodological, but are rather about the nature of the person and the personal realm in relation to which, and about which, linguistically constituted forms are produced. Being a native to the place in which I am confined by the class processes constitutive of the lives of people in the north of England, I do not have a problem interacting with a wide array of people who are common to the areas in which we move as people rendered common by the institutional processes of degradation that process us away from the central economic nodes of life for the middle classes who occupy institutional niches within cities.

Underlying all my interviewing practices, then, there is an underlying sharing of space, culture and life that 'speaks' for my authenticity - because who else would live here but someone born here? Presence therefore guarantees membership, because these are trapped communities. Bourdieu captures the importance of this:

Social proximity and familiarity in effect provide two of the social conditions of 'non-violent' communication. For one thing, when the researcher is socially very close to her respondent she provides her, by virtue of their interchangeability, with guarantees against the threat of having her subjective reasoning reduced to objective causes, and those choices that she experiences as free made to seem the effect of objective determinisms revealed by analysis... When...an unemployed worker [questions] another unemployed worker...with whom she shares virtually all the characteristics capable of operating as major explanatory factors of her practices and representations, and to whom she is linked by close familiarity, the rationale for the questions is found in her dispositions, which are objectively attuned to those of the respondent herself. Thus the most brutally objectifying questions will no longer appear threatening or aggressive because her interlocutor knows perfectly that she shares with her what she is inducing the other to divulge and, in the same way, shares the risks that the speaker exposes herself to by speaking about it. And the interviewer can never forget that by objectifying 
the respondent, she is also objectifying herself, as is attested by the adjustments she introduces into certain of her questions, moving from the objectivizing 'you' to 'one', which refers to an impersonal collective, and on then to 'we', in which she clearly states that she herself is involved in the objectification. (Bourdieu 1996:20)

This relation of familiarity meant that there was the possibility of establishing a sense of mutual involvement in the conditions and situations being discussed, which meant that interviews could become quite vivid mutual expressions of life and of some of the deepest, most troubling experiences of our culture, which would otherwise generally be glossed over or heavily euphemised because of propriety. The situation thus became:

...a two-handed socio-analysis, in which the analyst is herself caught up and examined, much as the person she is submitting to investigation. (ibid:21)

In these conditions, what occurred was an objectification by participants in which the participants would struggle to articulate the hidden principles of their lives, the externality that they experienced and which their practice accommodated (see Charlesworth 2000a:131-149).

Because of the nature of my life as someone who has been unemployed on-and-off since 1985, I have always been around particular sites that one might dignify as 'research locations' that have facilitated the analysis of the phenomena around me. Moreover, we have to situate studenthood in relation to a higher educational field that serves the middle classes who selectively process students in relation to their origins as they are inscribed in embodied traces of their resources and background. For many working class students, studenthood no longer represents a break with their native conditions because of the poverty studenthood involves. Hence, for many working class students, to study is no longer to be on an incorporating trajectory, because their experience of university is not integrating and they usually remain in their community of origin, as the words of a 24-year old graduate evidence:

Ah mean Ah didn't live in Sheffield when I was at uni, so Ah never saw the tutors. Ah 'ad t' get the books an' w'k from home on mi Dad's PC. I couldn't afford to bi guin' to uni' everyday, ${ }^{4}$ it would have been easier with a lap top ${ }^{5}$

\footnotetext{
${ }^{4}$ What this makes clear is that the realm of actualisation that is available for working class students is to 'choose' to live within a highly circumscribed privatised realm that is not of the public world at all. From this condition they cannot begin to acquire, mimetically, the forms of comportment against which they will be truly judged in relation to a student body constituted from those who can afford to live in or around the campus and socialise with students because they embody the forms of capital necessary to solicit their interest. What this manifests is that the only choice available to working class students is to choose to be culturally immobilised, working alone, in isolation, on topics that relate to nothing immediate for satisfactions that are never forthcoming. I think this sums up something fundamental about the working class experience of studenthood: it reproduces precisely the cultural condition of the working class: immobilised by a cultural and institutional sphere that leaves them nothing available that is worthwhile. In terms of a capacity to act in a world, the working class are better off within their own realm, among their own kind. There is no sphere of action actualised for students of working class origin. Moreover, what is clear is that for such students, their studenthood, indeed, their education, takes the form of an illusion that they are unable to believe. What has been constituted for working class students is an illusion organised with the complicity of the agents of the civil sphere so that those agents can have the illusion of their own identities made real through interpersonal forms whose terms of constitution affirm their public identity. We can see why Bourdieu says, 'students do not all have an equally false relation to their present position, because the future is not equally unreal', rather 'their objective future imposes itself so clearly that mystification can never...succeed, so that the key to a good deal of their behaviour can only be found in the objective truth of their situation' (Bourdieu
} 
but I used to look at it, an' think "easier or five or six hundred quid in bank". I buy things that I need, I live by mi needs.

Living by one's needs clearly involves living through the available opportunities to someone of a particular income, it means living like a working class person with working class people. Hence, a presentation of my 'research' as 'research' involves a lie: a lie arising from the instituted fraud that British higher education involves for many from the poorest regions of the country. Just as many of us were never at university, so too are we not carrying out 'research', but merely involving ourselves in a co-constitution of the terms of our lives.

Hence, if I were to euphemise and authorise my 'research gathering practice' in order to meet the representational criteria of an anthropology journal, I would have to say something like the following: I have used participant observation and open-ended interviews at several research locations: local gyms, pubs and nightclubs, the unemployment centre, the local college, the Department of Social Security, and Job Centres. These are suitable spaces to get a sense of contemporary working class life. These are spaces where the 'socially excluded' manifest their being-excluded-as every middle class parent knows, they don't want their kids to be with people who congregate in gyms, access work through the Job Centre and go to tertiary colleges. Whilst these spaces appear discontinuous, they offer a topographical network that will unify the biographical information. That is, together, in ethnographic detail they represent a landscape across which biographies can be mapped; they are locations which are tied together by their contribution to a distinct culture which is constant across disparate social spaces. I have therefore, from necessity, devised a form of ethnography that combines observation and episodic testimonies with more detailed biographical accounts. The research sites are thus sensitive areas of social space, strategic research sites, within which people come into being and which require a complex multi-dimensional socio-analysis (Bourdieu 2000a) through which one can re-trace the processes of identity formation and habituation that are the root of lifestyle practices. The basic method is a form of triangulation: a sampling process that has taken place over 12 years involving a cross section of people at the research sites who are good 'historians' of their own conditions, with whom I have used highly

1979:57). Working class students never get the respect associated with student-status in the former state of the field, and then on the labour market they do not get the respect actually associated with the credentials as they were constituted in the former state of the field. We should not be surprised that, 'Long gone are the days of leather book bags, of neat, proper clothing, of respect shown to teachersthe many signs of belonging that lower-class children used to give the school system and which have since given way to a more distant relationship: disenchanted resignation disguised as careless nonchalance is displayed in the ostentatious lack of school material - the files held by string or rubber band that they drag along over their shoulders, disposable felt pens that take the place of the expensive fountain pens they used to get on birthdays and similar occasions to encourage them in their studies. It is also visible in the increasing provocation to teachers, like listening to a Walkman in class or dressing in blatantly informal clothes which often carry the names of the latest rock groups - so many reminders right in the middle of school that the "real world" is elsewhere' (Bourdieu 2000b:425).

5 What this evidences is that the very form of study is delineated by penury, with working class students not being able to afford the technological means to enhance their learning and their growth. A local student studying Music Production told me how he couldn't afford a PC whereas students on the course had their own studios worth several thousands of pounds. We see how the realm of selfrealisation and of personal development of working class people is thoroughly curtailed by the realm of the available. Indeed, from such a condition, all one could really do is constitute oneself intellectually in relation to the depth of one's experience of impoverishment: this, in the contemporary period, would be one's richest experience and the source of any possible cognitive development. 
interactive, lengthy interviews, often recorded, in order to allow what is a repressed discourse about the experience of the social to emerge.

What is euphemistically described here is not very different to being unemployed or being working class. Indeed, it feels insincere of me to attempt to dignify what I have done as 'research'. Because of-as I see it - the pointless nature of social science education in the UK, and the worthlessness of the credentials, I was just someone having to live in the area in which I was born because I lacked the resources to socialise around the universities that I have studied at. The lives of the people around me, are, hopefully, articulated in this work, but to dignify what I do as research seems a little fanciful. Indeed, that it has to be dignified in these euphemising, technical terms, in order to get published, tells us much about social science as a disciplinary form: methodologies too often seem to be contrivances for those who are not part of what they study and for whom there is a problem of contact because they are buying their way away from the phenomena of ordinary life. It's a point well made by a 39year old anthropology graduate:

...what's troubling is they should sacrifice any credibility but what's so shocking is that they constitute their own knowledge of the social as knowledge, they constitute themselves as knowledgeable, through their ignorance of the social, they don't live in the world, so they don't know it so they are free to go off and 'discover' poverty or 'discover' the face of the inner city, the rest of us fuckin' live it, we don't lay claim to knowledge 'cos we can't dignify our practical understanding in this legitimacy, by this class magic, this is what constitutes their knowledge because they are so alienated from it and it is just the most banal rubbish, the mere fact that it is such a problematic activity for them, knowing the social, that they write theories and methodologies about what is immediate to the rest of us just gives you the fuckin' lie of their social estrangement...

Bourdieu makes a similar point:

Because theory - the word itself says so - is a spectacle, which can only be understood from a viewpoint away from the stage on which the action is played out, the distance lies perhaps not so much where it is usually looked for, in the gap between cultural traditions, as in the gulf between two relations to the world, one theoretical, the other practical. It is consequently associated in reality with a social distance, which has to be recognized as such and whose true principle, a difference in distance from necessity, has to be understood, failing which one is liable to attribute to a gap between 'cultures' or 'mentalities' what is in fact an effect of the gap between social conditions (also arising in the anthropologist's native experience in the form of class difference). Familiarity, which books cannot give, with the practical mode of existence of those who do not have the freedom to distance the world can thus be the basis both of a more acute awareness of distance and of a real proximity, a kind of solidarity beyond cultural differences. (Bourdieu 1990:14-15)

In other words, to exhibit solidarity with the poor allows one to understand the depth of the difference that being poor is.

\section{Incoherent lives, despair and strain}

It has emerged clearly that job insecurity is now everywhere... it produces...identical effects...particularly visible in the...case of the 
unemployed: the destructuring of existence, which is deprived...of its temporal structures, and the ensuing deteriorization of the whole relationship to the world, time and space. Casualization profoundly affects the person who suffers it: by making the whole future uncertain, it prevents all rational anticipation and...belief and hope in the future... The awareness of it never goes away: it is present at every moment... It pervades both the conscious and the unconscious mind... Objective insecurity gives rise to a generalized subjective insecurity which is now affecting workers... (Bourdieu 1998:82)

In order to situate Bourdieu's analysis, it is worth considering an interview that I conducted with a 28-year old machine-operative who regularly has to move between jobs:

S: ...yer said yer stressed... can I ask yer to se' sumat abaht 'ahr it manifests itself in yer life?

$\mathrm{X}$ : Ye... [sighs and pauses] ...'cos yer just constantly on an edge, know what I mean, yer constantly on an edge, yer thinkin' all time, yer gu to bed at night an' yer laid the'er thinkin', I mean, "What 'appens if I'm made redundant? Well I'll lose this 'ahse [house] I've worked up, I've worked to build this up, everythin' I've worked fo an' built up", yer worried, yer thinkin' all't time that yer gunna lose it, just becos ' $r$ someb'dy teks yer job off yer, everythin' else can bi taken off yer, an' yer just, yer just constantly under stress an' on an edge, know what I mean... Yer can't enjoy yerself when yer gu' aht, 'cos yer stood the'er thinkin', yer mates ' $r$ stood the'er on abaht sumat else an' you're stood the'er thinkin' 'Fuckin' ell, I can't bi du'in' this an' I shun't bi du'in' this an' Ah shun't be duin' that', every time yer put petrol in car just t' gu' aht, yer thinkin' "Fuckin' ell that's a tenna gone"... Well, I mean, that's just wo' it's like.

S: ...yer sufferin' from depression, can yer talk abaht that...

X: I, I'm...tearful. Ah'll bi sat wi' telly on an' ah'll bi like wellin' up, yer guin' aht, yer walkin', like a lead weight on yer, it's the'er all time, yer know yer can't get away from it, even if, like Ah've found somewhe'er else, next week, but it's fuckin' shit an' it's all same everywhe'er in ma game, know what Ah'm sayin'?

S: ...does being conscious of spending interfere with yer night aht?

$\mathrm{X}$ : Well, yer know, it's shit, 'cos yer can't relax, yer know, yer can't talk abaht owt, yer feelin' worried, it is, as Ah se', the'er, all time, an' yer mates 'll bi 'avin' a crack an' yer stood the'er thinkin', "what if Ah lose ahse, what if Ah can't run car, what if Ah can't afford to come aht?"... Wiy'aht money yer can't do nowt, lads 'll stop callin' if thy an't got money to gu aht, so yer need the coin.

The reality of the destructuring of existence and the deteriorisation of the relationship to the world is manifest in the dis-absorption of this person's capacity to project into the everyday aspects of working class life, and from the changed relationship to the medium of exchange that work provides: money. What is clear from this is the way in which this insecurity affects an individual's capacity to relate.

\section{Visibility, the interpersonal and experience}

What I think is becoming clear, is that income dominates one's capacity to appear: how we are able to appear is determined by the resources that we can invest in 
processes that affect our access to the interpersonal: the means by which we acquire, mimetically, the grounds of our appearance: as class is biologised and we face a world disclosed in relation to the public meaning of our marks: this is how position is reproduced. Hence, what is determinative of a sense of being is the way in which the public realm is constituted. The public realm is constituted by those with the money to be recognised, positively, and thus solicit the contacts necessary to 'succeed' through the mediating interpersonal and institutional processes than now constitute access to labour markets outside of the working class.

The middle classes realise themselves in the public domain, a realm framed interpersonally to facilitate an experience of freedom and of subject-hood that is embedded in a recognition realised differentially, in relation to those they efface and degrade:

...because of the essentially diacritical, differential and distinctive nature of symbolic power, the rise of the distinguished class to Being has, as an inevitable counterpart, the slide of the complementary class into Nothingness or the lowest Being. (Bourdieu 1991:126)

Since forms of being require the forms of contact involved in being-perceived appropriately in terms of lived interpretations of significant forms, comportmentally tied to mimetically acquired aspects of being, public identities can be protected from appropriation by the very terms of their interpersonal constitution. Currently, as only 40 per cent of UK graduates get graduate jobs, it would seem fair to say that access to meaningful lives is being constituted to be exclusive. For those who do try to access spaces constituted to produce the tokens necessary for success through exclusive forms of association, in public institutions, it is not surprising that working class people experience the weight of their negative visibility, experience their inability to show-up as viable instantiations of personhood. As a 22-year old unemployed man who is a recent graduate put it:

...what can yer du? Yer can't do nothin', they just look right through yer, ahr can yer even get t' talk to 'em? Thi' act like yer not the'er.

Arendt (1968) stressed the importance of this public realm as a means of our beingseen and heard, assured of our reality, and it is not surprising that this testimony links being-perceived as conditional to forms of contact, such that being negatively signified precludes the chance of speaking. Hegel (1977) understood the personal necessity of existing in an actuality that was publicly affirmed by our beingrecognised in relation to the forms of value determinative of association in relation to distinct forms of personhood. And he stressed that the urban bourgeoisie dominate public life. The experience of working class people who stray into middle class spaces is something akin to the experience of conspicuousness that Fanon described as the experience of 'thatness', the experience of 'facticity' felt in the medium through which it is realized, felt through the flesh's kinaesthetic awareness of itself in relation to others. As the words of a 30-year old Asian evidence:

$\mathrm{Ah}$ become all conscious, of ma weight, Ah felt overweight, Ah start swettin', Ah start bunglin', shufflin'... yer feel "Ah shun't bi there"... yer know you insult them, an' yer hate them fo' it...it's like a barrier sayin' "listen' low life don't even [voice rises with pain and anger] COME NEAR $M E$ !" ... yer know ahr they feel, yer feel it... it's that air abaht 'em, yer know, thi've got the right, the body, the clothes, an' everythin'... an't got it, wi... Wi' walk in like wi' been beaten...draggin' ahr feet when wi' walkin' in...yer like feel like yer want to hide... 
There is much of interest here, but the spontaneous relation of 'thi've got the right, the body, the clothes, an' everythin" makes a link between form of appearance and actually possessing the prerequisites to show up as a person befitting of contacts that bequeath opportunities to be realised as a person possessed of distinct forms of subject-hood, as opposed to something merely there, 'invisibly', in the manner of furniture and usable items that merely witness more meaningful aspects of engagement. People are consigned to silence by the terms of their appearing, by how their appearance, their 'sense', is constituted in a public domain dominated by the value of the marks of income: economic capital: money. Their public silence is assured by the forms of contact that issue from the articulated patterns constitutive of the public space of state institutions in which middle class apparatchiks work. As a 45-year old manual worker recounted:

...Ah've a mate an' wi' wo' guin' in this snotty boozer, full'r snobby cunts, an' mi mate ses, "the're aren't many in 'ere who earn what we earn", 'cos hi wo' on abaht six 'undred, Ah wo' on abaht five, but Ah ses, "ahr but it in't just money is it", hi' ses, "naow the stuck up bastards can tell-yer, it's written all o'r yer, it's in ahr yer carry yerseln"”, Ah ses "ahr, but Ah'm dressed up, nowt fuckin' wrong wi' me", hi ses to me, "ahr yer build'll giy yer away, tha's no chance, tha'r a big ugly cunt”, Ah ses, "well Ah fuckin' w'k, it's fuckin' 'ard earned ma money", hi ses, as soon as yer walk in thi've got us spotted, Ah ses, 'avin' a joke like, "ahr, like no women come near us do' thi", an' hi ses, "thi've got us so'orted man, tha' can't hide thi'seln' Pete" an' $\mathrm{Ah}$ allous remember 'im sayin that to me, [pauses reflectively, eyes down] ahr, hi said "yer can't hide", an' hi's rait, yer can dress yerseln' up, yer might think yer' look rait; underneath thi'll see...

And these processes are encountered in other public spaces by other sections of the working class. As the words of a 24-year old graduate of Sheffield Hallam University make clear:

Well thi'...like mek yer be outside their little world, like mekin' yer different, thi' like se' things so that only those like them can be part'r it, it's not open at all. Ye'd see it in ahr thi'd sit together in lectures an' stuff. Thi'd like gu in an auditorium wi' different levels'r seats, thi'd all congregate, thi'd all sit together an' Ah found miseln' on mi own, but thi'd slag lecturer off, tek piss, then thi'd be totally different t' the'r faces...

What is manifest here is that there are those who are a group 'in civil society that is not of civil society' (Wood 1993:423), people whose public significance arises from the interests constitutive of the public domain, so that the sense-relations constituted from the significances established through un-codified exchanges, or instantiated differences, operate to 'magnify' differences in regard of position so that even the slightest of differences, even members of one group being 'dressed-up', are signified in regard of the practical intentionality constitutive of this domain. The result is that working class people are uglified (Young 1990), negatively visible, so that selfconsciousness, disclosed in responses that render individuals practically aware of the terms of their being-perceived as terms they must practically 'respond' to, becomes a medium in which they experience themselves partialised, separated from the terms of their being-in-that-context, such that their contextual negation forces terms of selfunderstanding that separate them from their reason for entering the context. The instantiated segregation they encounter leads them to separate and return to spaces in which they can be humanly recognised, in which they can exist through forms of personhood that involve a basic subject-hood. 


\section{Exclusion and forms of access to being: maladies of the flesh as it is publicly signified, interpersonally disclosed and personally lived}

When people start to live-because of these spatialising (interpersonal) processes that consign individuals to a sense of themselves that confines them, by sense, to a distinct realm that they are attuned to because of such processes - as if they have no living relation to human forms of being, then perhaps we need to begin to find other approaches to human being that can treat conditions in which it is unrealisable. In order to contextualise these issues, I would like to use the words of a 40-year old man who hanged himself. Six weeks before he did so, he wrote the following to me:

The lack of opportunity to indulge in the adult forms of play is one of the hardest consequences to bear as a result of being stigmatized... Even a prisoner has contact with other prisoners... I can't describe how low I feel. I have been out with the dog at $8 \mathrm{am}$, and when I came home, it felt like I was coming back to a prison cell. I am now pacing up and down, anxious about things that I can't quite resolve inside me. There are things I can do; they are things I should push myself to do to get away from this pervasive fog of worthlessness that I am smothered by, but I can't muster any interest or determination... My decision making ability is terrible at the moment, and I feel impulsive, wracked with guilt at my enforced idleness, demeaned, worthless, and generally miserable... I cannot permit myself to feel ok now, because I fear that if I do I will simply remain static as a result of allowing myself contentment with the present, so I torture myself - to try to make myself move on (?) -- but where can I go, and what value do I have? The irony is that I am regarded as neither a debit nor a credit to society, I am a zero, and that 'nothing at all' value is a destroying experience. I am neither light nor shadow, because I am invisible... In my head I am stood at a thick plate glass window, watching everybody else on the other side. I can hear them, but they can't hear me, and although they can see me, they don't need to glance my way, and so I never get eye contact. Anxiety stops me from curling my hand into a fist and banging on the window, just in case everyone stops momentarily, and then continues regardless. ${ }^{6}$

Unable to be sanctified, recognised, individuals are unable to secure involvement and unable to be realised in relation to others because they do not have anything that anybody wants. Their worlds implode because their world is private, their being-in-aworld is disclosed in relation to others by the privation of their position:

I have never been able to integrate myself into any clique because I find them suffocating and there is often a leader, a person of little charisma who acts like the leader of a monkey troop. It is usually the man who can drink most, has the flashest car, shags the most birds and so on... all of the inconsequential qualities catapult him into some position of authority in his social group. Where groups of girls are concerned, the leader of the gang is usually the prettiest, or has the biggest tits, or some other facile reason for being able to dictate the activities and shared goals of the clique, they then go for the lads who're the leaders, an' if yer not integrated, you end up alone. [33-year old manual worker]

This quotation makes clear the practical forms that capital is constituted in, and the problems that those least possessed of economic capital have in being realised, interpersonally, as a social being: a person. Clearly, with the person negatively

\footnotetext{
${ }^{6}$ His words are testament to the loss of talent that our contemporary economy requires for its particular efficiency.
} 
signified in their flesh as an absence of the necessary marks of human value, the experience of limitation, born of being negated, affects the forms that perception takes because perception issues from disclosures, realised interpersonally, that indicate one's essential meaning. Those lacking value lack any personal means of being realised because they cannot solicit recognition, cannot elicit a glance that might bequeath an opening to actually speak or converse. The person's infraconscious sensibility, the affective realm of biochemical signals that is the sympathetic nervous system from which cognition issues, becomes dominated by the circumscribed mode of their being: they exist within a limited circle of the same interpersonal forms and a few streets and their being becomes dominated by its negated capacities, human power magnified by its projective nature, ${ }^{7}$ into utterly desolating affective forms, inductive of mental illness and hyper-consciousness of finitude. A 30-year old unemployed man seems to render the experience in an interesting way:

Yer've no externality, yer become totally absorbed in yer self, yer know, Ah never 'ave contact with other people, yer turn in on yourself so yer do become aware of yer skin, you become acutely aware of how you look. Yer become like a hyper-chondriac. Yer start to focus on yer own heartbeat... Ah get up, there's nothin' to do... so Ah'm holding onto morsals, things to do cos once it's finished... Ah can't relax... It in't a life... Ah need stimulation! ... Ah'm tryin' not to care abaht owt, but Ah can't. I could live ok on benefit, but this in't nothin', Ah'm more than the nucleus of mi own life... Ah'm more than a single celled organism.

This makes clear the relation between perception and privation: ${ }^{8}$ how an existence made asocial by lack of value and the inability to find meaningful public relational forms through employment and status forces an individual into a privatised world that cannot be escaped. Furthermore, without a realm of determinate possibilities in regard of which individuals can be realised in relation to others, recognised as subjects and persons in confluence of relations constituted around their form of subject-hood, there is no means of self-actualisation, and as Hegel (1977:82) put it, 'it is impossible for him to live in a way appropriate to his estate if his estate does not exist': there is no means of fruition in a world in which individuals are redundant. Individuals are selfactualised only in relation to forms of inter-relation, whose individual condition is possession of the marks of value. These forms of value are generated within particular communities. Those without the means to mediate access, personally, become mired in an inability to access the personal forms necessary to access sociality.

Recognition is a central aspect because how one is perceived: as worthwhile or useful, is central to human contact. Interpersonal contact is preceded by how one is perceived in terms of the value that is constitutive of any given space, mirrored in the forms or 'styles' necessary to enter a space. Hegel makes this dynamic explicit when he says

\footnotetext{
${ }^{7}$ That is to say that being always presses: we are burdened with existence as a form that we must be: hence, from what is mimetically acquired, as the dispositional forms of being that we inherit from the people who constitute our localities, we inherit the forms through which we attempt to realise ourselves as social creatures: we have particular modes of address, particular perceptions in regard of our markedness that determine the range of our forms of engagement. Being is projective in the sense that we constantly utilise it in an attempt to be in terms other than we are forced to accept. For some these attempts must fail.

${ }^{8}$ That is, the way in which income affects treatment which affects what one perceives, fundamentally about oneself, which affects comportment and in turn forms of access to interpersonal forms that circumscribe existence and fundamentally affect not only relation-to-being, presence, and others, but the whole affective-realm from which perception issues.
} 
'[s]elf-consciousness exists in and for itself when, by the fact that, it so exists for another; that is, it exists only in being acknowledged' (1977:111). Without acknowledgement, without the contact that shows that one matters to others in determinate ways that affirm one as consequential, our personal status as members of a human community falls into question: 'Nobody wants yer if yer an't got any money, 'cos yer no use to them, that's ahr it is, it's rent-yer-mates nahr, that's ahr it is.' With the souls of those without the means to solicit contact becoming terrains of negation endured physiologically through a constant experience of strain and pain, it is hardly surprising that non-existence becomes a necessity to be actualised in order to escape a tortuous experience of nothingness coursing through one's veins and sinew, haunting the habitat of the body as it is turned against itself by forms of being that are actualised against one's own inherent capacities: human sensibility collapsing into the mechanics of an impoverished form of being. As the words of a 55-year old exsteelworker make clear:

What it is wi' me, wi' workin' class, is that we are so brutal, we 'ave to be... we have to learn to be happy wi' our pain, it is like that, Ah mean if somebody ses "are you happy?" Ah don't even know what that means or ahr to gu abaht answerin' it, to me it means, "Am I wet", no Ah'm dry, "Am Ah in danger", no Ah'm safe, "Am Ah in pain", no, "is owt impacting on me", no, well Ah must be alright so Ah must be happy. Which is why everythin' just alright, like them jokes abaht the Yorkshire man who just ses "alright", an' alright means "It's fuckin' brilliant", if hi ses "it's alright", it means it must be fuckin' great, 'cos that's all the're is, like you have an understanding of beer, you can tell the good stuff an' the rest, well Ah can't, to me, beer's beer, it's wet an' it gets yer pissed an' gi's mi headache if Ah drink too much, to me beer's beer, it's either alrait or shite, an' that's it to me, Ah don't 'ave qualities in mi life, everythin' just alright... That's ahr life is, tha's gorra bi happy wiy' it, that's why thi' se' "get aht'r mi 'ead", [taps head angrily] 'cos Ah ain't fuckin' livin' in 'ere no mo'ore, Ah'm fuckin' sick'r it, let me aht.

Again, this makes stark the way in which privation, lack of income, lack of the capacity to buy commodities that allow one to be realised, socially, to be wanted, affects a person's experience of being-a-person. It makes stark the qualitative terrain of absence that is endured, the lack of anything worthwhile bequeathing lives of pained endurance that require chemical aid, 'mi medicine', to live. Without personal access to the interpersonal forms necessary to be actualised in one's humanity as a socially mediated essentiality, one experiences inessentiality, one experiences being as non-being, as symbolic death and reduction: as pain, frustration, and one becomes dispossessed of one's initiative. Will-less: 'A will that resolves on nothing is not an actual will' (Hegel 1992:47). One becomes will-less because the conditions of having a will, of experiencing intentionality, of being able to project with confidence into determinate projects, involves being able to mimetically appropriate, personally acquire, physically embody, the forms necessary to solicit engagement: the condition of being realised: fulfilled. With being so reduced to a realm in which the ready-tohand is the private space ever-imploding into the sensuous medium of the flesh, it is hardly surprising that the medium responsible for cueing our significance, the medium signified against itself: the flesh, becomes the object of experience for the subject it grounds. As a 29-year old taxi driver put it:

Ah just feel scruffy all the time... it's like thi's somethin' up with ma skin...

Ah'm on anti-depressants but it dun't mek no difference, Ah dun't feel 
better, yer know yer go aht, yer judged all the time, soon as yer walk in a place, Ah'd sooner stay aht ' $r$ that shit.

This makes one feel that the skin, the epidermis of the human organism, becomes affected, in the nature of its sensitivity of itself, by the terms of its perception: we can see why Merleau-Ponty focussed upon its peculiar status as medium and object (Merleau-Ponty 1962).

\section{Conclusion: trying to care: indifference and despair as ontological conditions}

This paper began life two years ago, as a meditation on the suicide of someone from the village in which I live. I've tried to publish a longer version but academia is as resistant to evidence as it is immunised by the lack of care of those who personnel it. Obviously, I have tried to present an analysis that moves from the particular interpersonal forms of neo-liberalism to a characterisation of the personal terms that people perceive about-them in the human world that is interpersonally disclosed forthem in their relations with others. Value and perception are closely related because both issue from sense, which is an attribute of human being that renders our natures existential. Even our biology is affected by our social significance (Wilkinson 2000) as it is interpersonally disclosed and thus realised.

To consider social conditions is to consider the personal terms through which social conditions are realised. The terms of the three suicides were clearly similar: penury; debt; drugs; partner-trouble. In an age in which borrowing from friends and family has become a major factor of life for the bottom third of society, it is little wonder that the interpersonal forms of their lives has become as infected with the problem that money is, as their terms of self-realisation and experience have become by the problem of their value. Negated on so many terrains simultaneously, being, existing, becomes a struggle, as the words of a 32-year old self-employed businessman put it:

The areas we live in [are] so hostile, it's a war zone, bad enough discrimination in work and what not, but going to corner shop's fuckin' aggro. Ah just live 'ere, gi' mi a million pound, it's that desperate, Ah live in this fucking society what more can a person do? Yer know. It's so hard, yer deserve payin' just to live 'ere. It's vicious time, yer...yer too preoccupied to fight fo' any rights. I an't got a prayer, what I can earn, earn nahr, in a legit job is 200 quid, famly 'r four! Alrait we're sufferin' what chance 'ave our bastard kids got, not a bastard chance. Fuckin' money's gettin' scarcer at our level, fuckin' 'arder an' 'arder to get buy, money's more an' more scarce, you earn' fo' the basic essentials, to get the fuckin' basic shittest life. Fuck me Simon, time's a killer, what can yer fuckin' do? Yer can't do nothin'. We actually look fo' a menial prison sentence to kill the boredom, what can yer do? Yer end up not bein' arsed to do anythin'; the's nowt worth doin'.

What is manifest here is the way in which relation to time becomes haunted by reduction, by powerlessness, by inability, by the grounds of this ontological reduction which actually changes the deepest aspects of our rootedness in being-'Fuck me Simon, time's a killer, what can yer fuckin' do? Yer can't do nothin'. We actually look fo' a menial prison sentence to kill the boredom'-time transmutes into an experience of being, rooted in worthlessness, time becomes something that, like boredom, must be 'killed'. At the end of this conversation, this person joked, 'Ok Simon, I'm goin' to go back to mi trance'. It makes explicit, again, the retreat to 
forms of being that are devoid of acute cognisance, devoid of self-concentrated moments of being-there, devoid of the experience of the failed projection of attempting to live in the moment as an elucidation of one's engagement, such that one, spontaneously, retreats from the immanent experience of being-there in order to erase the failure of being involved in one's conditions of being. Instead, in the absence of a realm of reciprocal actualisation, the individual lives on a terrain of being that is reduced, thoroughly, by its public terms of encounter, 'Ah live in this fucking society what more can a person do? Yer know. It's so hard, yer deserve payin' just to live 'ere. It's vicious time, yer...yer too preoccupied to fight fo' any rights'; or as another man articulated it, '... wi' too fuckin' busy fightin' to keep what wi' 'ave, to du owt'. The multitude live their public status as an acute personal individuation that atomises and pathologises their way of being such that we should not be surprised that their 'actions' are lacking in humanity.

The paradox of this desperate attempt not to care, to reach a state of indifference to mattering at all, is that it arises because not mattering at all, and having nothing to value, such that one must constitute oneself in terms of a refusal of the human terrain of commitment, of concern, is the ultimate experience of the futility of those who lack the social value to accede to a 'to a socially recognized' form of 'social being, in a word, to humanity' (Bourdieu 2000a:242). As soon as one cares or wants or desires, as soon as anyone else matters, one faces one's poverty and the poverty of one's flesh, the flesh responsible for one's personal failure, to be manifest positively, in one's being for another, and the only remedy is this desperate, constant, vigilance to ensure that nothing arises that matters, the constant circumspectively realised attempt to let nothing matter, to want nothing and thereby be content with being nothing:

...do you see any of us content or satisfied, we daren't even try and ask for anything... it's like that thing, yer know, "we're not worthy"... wiyout any form of understandin', wiyaht any education, wiyaht knowin' what things wi' could 'ave, wi' want more, wi' all want humanity and comfort, but wi' can't 'ave it. Yer want without the money you're gonna suffer. [36-year old delivery driver]

There is little wonder that this man has to turn to different kinds of legal and illegal chemical substances to help him cope with being nothing, with an experience of his own, most essential, intimate self as unable to be a socially realised, personally useful, human being:

...that's why Ah tek the tablets, thi' 'elp yer not want. You don't allow yerslf to want owt, if yer allow yerself to hope fo' anythin' yer get angry, fustrated, pissed off, ye' ave to keep it real, yer focus 'Ah'm useless, this is it, deal with it", as soon as yer want someaht that's when yer fucked. Ah tell yer pall, wi live in a prison.

We see why, for the dominated, the question is not humanity but being: presence. There is little wonder that the temporal patterns of life are constituted in terms of patterns of avoidance, a life lived nocturnally, when the light of every day does not constitute visibility radiantly:

Went to doctors today... Thi' med mi see this nurse... Nurse-counselor, whatever, thi' an't got a fuckin' clue, but it's way thi' talk t' yer, things thi' se', thi' just dun't get ahr lives... thi've no idea, shi asked me ahr Ah feel, yer think "where do yer start", Ah ses "Ah don't like gettin' up, dun't like goin' aht, don't like days, hate light, prefer night's so' Ah stay up late, chillin'", shi's talkin', Ah'm sittin' the'er thinkin' "you an't got a clue". 
Thi've no idea. All the'r interested in is, "are you goin to hurt anyone?" Thi' can't relate to our problems... How we live they an't got a fuckin' idea we might as well bi in totally different countries, that's why they find it so hard to understand us... thi' se' "Why do you do that?", it's not aht'r choice, thi' se' "why can't yer do this", it's fuckin' unreal, we think "Fuck me! Ah wish Ah'd thought of that"... yer just gu quiet... [33-year old labourer]

\section{Epilogue: whither political wisdom}

The politicians have co-produced this state of affairs, which makes the history of political thought more relevant as a form of contestation of forms issuing from social power. Moreover, the history of political thought is crucial to our capacity to represent forms of human misery, tied to forms of human bondage, originating in the economic and public domain. Without ideas to elucidate forms of experience, we have no means of representation and those most in need of representation will continue to perceive political discourse as irrelevant and their exclusion will continue. The words of one 53-year old ex-steelworker capture the UK's situation:

$\mathrm{X}$ : ...the maxinimum, the very maximum, the furthest thi' can see in future is, payin' the car off, 'cos then "Ah can get a better car! Ah can get another one then! Get another car. Fed up wi' this bastard!' The're fuckin' 'ouses, that's like a long-term thing, thi' 'ave trouble payin' that bastard so that's just the'er, yer know, thi' cannot see further than the next day thi' need to pay the're fuckin' bills. The jobs that Ah've done, yer can't count on yer fingers an' yer 'ands, on yer fingers an' yer toes, sorry, an' Ah look at Kilroy, or Jerry Springer, or Trisha, on' all them, an' Ah look an' think [voice drops in sadness] "Ah dun't understand any'r that? Ah dun't understand what that wo' abaht", an' Ah know what it said it was, Ah dun't understand what place it 'as in the world, an' if Ah can't look at someb'dy like fuckin' Kilroy an' understand what hi's fuckin' place in world is, ahr the fuckin' 'ell Ah'm a gunna supposed to bi' fuckin' whe'er Ah'm fuckin' supposed to be, so wi don't! Ah'll get up in mornin', on Tuesday mornin' when Ah gu back to work, Ah'll get up an' blunder mi' way through again', the fact that Ah'm dealin' wi' real people wi' real problems, these are real fuckin' people wi' fuckin' real problems, not fuckin' academic, if Ah drop a bollock, someb'dy dun't get the're benefit an' kids gu' 'ungry, if Ah fuck up, some kid gets abused, 'cos one way or another, even if it's a smart comment from mother or father, one way or another, some fucker's sufferin', an' Ah dun't know what Ah'm doin', Ah'm ohnny blunderin' mi way through, so...so, Ah'm not surprised that the're are a group'r people, that can become, once thi' become an elite status like that, that thi' dun't understand us, 'cos wi' fuckin' dun't, an' another thing that dun't surprise mi is that when thi' get that elite status thi' want, that thi' can protect it so vehemently, it dun't surprise mi an' it dun't surprise any other working class person, an' that's why thi' dun't giy a fuck, 'cos thi' can se' 'Ah'm ohnny doin' what Ah can do", "fuck them", "it's enough fo' me to worry abaht payin' fuckin' rent, it's enough fo' me t'e worry abaht ahr young 'un gettin' some breakfast, it's enough fo' mi to turn ma kids aht wi' decent shoy's [shoes], an' mek sure thi' gu to school an' mek sure thi' fuckin' turned aht on time, it's enough fo' me to get thi's kid to school, people who drive to school in a fuckin' Mercedes or a BMW to some fuckin' posh school, dun't fuckin' come int' ma fuckin' view, dun't see 'em, dun't exist to me! 'Cos every fucker Ah see is like me on this fuckin' estate" an' that is ahr it is, Simon, fo' most of us. 
S: Ah know, Ah know, Ah know.

X: An' nahr Simon, it's w'se 'cos nahr yer've got people, Ah see people, Ah work wi' people who get up an' the're question is ahr do Ah get my drugs fo' day, it's that fucked, nahr, thi've gone beyond the struggle that Ah knew, to w'k an' get by, nahr thi' get by any fuckin' way thi' can, an' politics means fuck all.

S: No, Ah know, Ah know. Yer see it everywhere if yer live places like this.

$\mathrm{X}$ : But the other thing is, that filters all way dahn line, Simon, because what's actually 'appenin' is, is, an' all the politicians will not admit this, they will not admit this, they mek hints, they won't come aht an' aht an admit, it, thi' mek hints that this might be so, but most workin' class people do not give a fuck fo' any politician, there's ohnny politicians understand the're own importance, an' so, thi' dun't se' "'owd [hold] on, wait a minute, so what's important to people's life?" Not the fact that whether it's Michael Howard or Tony Blair as Prime Minister [Voice rises in strain] It meks NO FUCKIN" DIFFERENCE WHATSOEVER. Throughout the seventies, throughout all the argument an' all thi' aggro against Margaret Thatcher, wo' just a trend because most people really did not fuckin' give a toss, 'cos all thi' wo' tranna do is catch a bus, to work, that's all thi' wo' tranna do, yer've got a bloke that wo' tranna think, "Well ahr can Ah get'a few mo'ore quid fo' that 'olid'y in Spain", 'cos again that's another trend, or ye'd got a single parent mother who wo' sayin', "Ahr do Ah get mi kids to school an' get to fuckin' Woolworths fo' nine o'clock, an' not get a bollockin' an' get mi wages docked?", so whether it wo' Tony Blair or what's 'is face 'oward, when yer think abaht whether Ah eat or not, or whether Ah've got anythin', yer know, or whether, yer know... or whether Ah'm ever Ah'm gunna actually get a night aht in next six months, an' bi able to afford a decent night aht in next six months, whether fuckin' Michael 'oward or Duncan fuckin' Smith or fuckin' Tony Blair or fuckin' Gordon Brown is on fuckin' stand, right, it dun't fuckin' enter int' the're fuckin' consciousness, it dun 't fuckin' matter. So, when [starts to laugh] they're tranna mek all these new, all these invitive [innovative or inventive or initiatives] ways'r bein' able to vote, an' ahr du wi' bring people back in to understand, an' 'ave some appreciative, enough to bi able to just turn aht an' put a cross somewhe'er, so, if thi' can't get someone to just se', 'ere's a piece'r paper, just write a cross on it, just cross anywhere, an' people'r sayin', 'Well Ah'm not fuckin' bothered, no fuckin' point", why can't it enter into any politicians 'ead, that thi' not actually fuckin' bothered.

\section{References}

Arendt, H. 1968. Men in Dark Times. New York: Harcourt Brace Jovanovish.

Bourdieu, P. 1979. Algeria 1960. Cambridge: Cambridge University Press. . 1990. The Logic of Practice. Cambridge: Cambridge University Press. 1991. Language and Symbolic Power. Cambridge: Polity Press. . 1993. Sociology in Question. London: Sage. . 1996. Understanding. Theory, Culture and Society 13(2), 17-37. 1998. Acts of Resistance. Cambridge: Polity Press. .2000a. Pascalian Meditations. Cambridge: Polity. 
. 2000b. The Weight of the World. Cambridge: Polity.

— 2005. The Social Structures of the Economy. Cambridge: Polity.

Charlesworth, S.J. 2000a. A Phenomenology of Working Class Experience. Cambridge: Cambridge University Press.

- 2000b. Bourdieu, social suffering and working class life. In Reading Bourdieu: On Culture and Society (ed.) B. Fowler, 49-64. Oxford: Blackwell.

- 2004. Northerners exposed: space and being. Reflections on working class experience. Space and Culture 7, 327-342.

- 2005. Understanding social suffering: a phenomenological investigation of the experience of inequality. Journal of Community and Applied Social Psychology 15, 1-17.

. 2006. Heidegger and understanding the urban poor: chemical solutions to the question of being. Practical Philosophy 8(1), 39-54.

Charlesworth, S., P. Gilfillan and R. Wilkinson. 2004. Living inferiority. In Cultures of Health, Cultures of Illness (eds) G.D. Smith and M. Shaw, 49-60. Oxford: Oxford University Press.

Hegel, G.W.F. 1977. Phenomenology of Spirit. Oxford: Oxford University Press.

— 1992. Hegel's Philosophy of Right. Cambridge: Cambridge University Press.

Heidegger, M. 1962. Being and Time. New York: Harper and Row.

Kirk, J. 2004. Injurious encounters. Space and Culture 7, 343-348.

Merleau-Ponty, M. 1962. Phenomenology of Perception. London: Routledge.

West, C. 1993. Race Matters. Boston: Beacon Press.

Wilkinson, R. 1996. Unhealthy Societies. London: Routledge.

— 2000. Mind the Gap. London: Weidenfield and Nicholson.

Wood, A. 1993. Hegel and Marxism. In The Cambridge Companion to Hegel (ed.) F.C. Beiser, 414-444. Cambridge: Cambridge University Press.

Young, M. 1990. Justice and the Politics of Difference. Princeton: Princeton University Press.

\section{About the author}

Simon J. Charlesworth is unemployed in Wath Upon Dearne, Rotherham, South Yorkshire. His email address is johnwck90@yahoo.co.uk 